\title{
COMMUNICATIVE LANGUAGE TEACHING AS CONCEPTUALIZED BY BHUTANESE ENGLISH AS SECOND LANGUAGE TEACHERS
}

\author{
Jigme Dorji \\ Pakshikha Central School, Ministry of Education, Bhutan \\ Email: bongopjigmee83@gmail.com
}

APA Citation: Dorji, J. (2017). Communicative language teaching as conceptualized by Bhutanese English as second language teachers. Indonesian EFL Journal, 3(1), 1-10

\begin{abstract}
The purpose of this qualitative study was to examine the conceptualization of communicative language teaching (CLT) by the English as Second Language (ESL) teachers in Chukha district in Bhutan. Four ESL teachers were selected as the participants for the semistructured interview through purposive sampling technique. A set of 15 predetermined openended questions on CLT were framed and asked based on Savignon's (1983) Foreign Language Attitude Survey Test (FLAST). The content validity of interview questions was ensured by consulting three experts and computing Item Object Congruence (IOC) in accordance with Lynn's (1986) item acceptability criteria. The data were analyzed using content analysis technique. The results revealed teachers' conceptualization under two categories; in compliance with and deviance from CLT principles. Under first category, the results showed that the participants believed CLT as a language teaching approach that focuses on developing communicative competence, teaching language for real life, child-centered teaching, and teaching culture in the second language classroom. Under the second category, the results indicated that the participants believed CLT as not using mother tongue in teaching English and only teaching listening and speaking skills. In addition, the study also uncovered the fact that ESL teachers are not aware of CLT approach. The article concludes with the discussion on the areas of training particularly relevant to this group of Bhutanese ESL teachers and recommendations for future studies.
\end{abstract}

Keywords: communicative competence, communicative language teaching, conceptualization

\section{INTRODUCTION}

Communicative Language Teaching (CLT) approach has become popular in the recent years as one of the most effective approaches to English as foreign and second language (EFL/ESL) teaching (Anderson, 1993; Chang, 2011). It is implemented in many EFL and ESL countries to enhance learners' communication skills in English. The approach emphasizes on developing communicative competence through the use of language in authentic context (Savignon, 1997). Despite its fame, implementation of CLT has confronted diverse challenges in EFL and ESL countries (Chang, 2011; Mangubhai, Marland, Dashwood \& Son, 2007; Savignon, 1997; Wu, 2008).

In Bhutan, English is used as an official language alongside Dzongkha, the national language. It is also taught as a major subject in schools besides using it as a medium of instruction for other subjects (Dorji, 2005; LaPrairie, 2013). Children learn English from Pre-Primary (PP) until college. Despite being exposed to the language from the early age, researchers have reported that children graduating from the schools and colleges have poor communicative competence in English (Dorji, 2005; LaPrairie, 2013; Royal Education Council [REC], 2012). In order to counter this issue, in 2006, a major English curriculum reformation came forward with incorporation of communicative components alongside the literature content (Curriculum and Professional Support Division [CAPSD], 2006; LaPrairie, 2013). However, it has been reported that, like in other contexts, Communicative components are inadequately emphasized and the language teaching practice has largely remained traditional (Kirkpatrick \& Gyem, 2012; LaPrairie, 2013; REC, 2012). Then, ineffective implementation of CLT has been partially 
attributed to teachers' unfulfilled aspiration in grasping the concept of communicative competence (Asassfeh, Khwaileh, Al-Shaboul \& Alshaboual, 2012).

In this regard, several studies are conducted to identify teachers' conceptualization of CLT in many nations within the framework of communicative competence (Feryok, 2008; Li, 1998, 2004; Mangubhai et al., 2007; Sato \& Kleinsasser, 1999). However, except for LaPrairie's (2013) study that concluded Bhutanese ESL teachers have lack theoretical knowledge about language enriching approaches, the teachers' conceptualization of a specific language teaching approach underscoring communicative competence such as CLT has scarcely been undertaken. Understanding teachers' conceptualization of the approach would provide an input for training and coaching for teachers' preparation and development in the area of CLT implementation. Thus, this study explored Bhutanese ESL teachers' conceptualization of CLT.

Hymes (1972) proposed the concept of communicative competence as ability to use language in a social context, observing sociolinguistic norms of appropriateness, feasibility, and possibility. Canale and Swain (1980) compounded different views from various disciplines to develop the communicative competence theory. According to Canale and Swain (1980), communicative competence refers to the knowledge and skills necessary for communication. It comprises of four components; grammatical competence, sociolinguistic competence, discourse competence, and strategic competence. Their theory has become an established theoretical framework for second language teaching and later became the fundamental principle of CLT.

\section{Characteristics and Principles of CLT}

Communicative language teaching is a learner-centered and experience-based view of second language teaching that develops learners' communicative competence (Richard \& Rodgers, 1986). In addition, Richard (2006, p. 2) offers a more comprehensive definition "communicative language teaching is a set of principles about the goals of language teaching, how learners learn a language, the kinds of classroom activities that best facilitate learning, and the roles of teachers and learners in the classroom." CLT as a language teaching approach emphasizes on the development of communication skills. The unique characteristics and principles of CLT distinguish it from the traditional teaching approaches.

According to Larssen-Freeman (2000), the most salient characteristic of CLT is to make the classroom interactive and communicative through activities such as information gathering, discussions, role plays, simulation, and problem solving. These activities help students communicate in different contexts and roles offering them the opportunities to get exposed to authentic language use (Richard, 2006; Savignon, 1982). This learner-centered approach emphasizes social relationship between the teacher and learner. The approach has been designed to give students a sense of "ownership" of their learning and enhance their motivation (Brown, 1994).

In addition, CLT aims at fostering sociolinguistic competence by making the students aware of the target language culture and appropriate norms of target language use, verbal as well as non-verbal. It is observed that sociolinguistic competence is instrumental in shaping learners' communicative competence besides language rules (Carnale \& Swain, 1983; Savignon, 1980).

CLT prepares learners to use the target language beyond classroom (Savignon, 1982). It engages students in conversation making through classroom activities, which engenders confidence in students to use language in everyday communication. The approach encourages students to use language in real-life context outside classroom.

Finally, CLT also seeks to develop learners' communicative competence by integrating grammar in context (Carnale 8 Swain, 1980; Richards, 2006; Savignon, 1983) and asking the students to carry out the task with reviews on relevant grammatical points. In short, grammar knowledge needs to be 
developed along with students'

communicative ability.

Conceptualization is an analytical process to examine a concept. In the process of conceptualization, first it takes to identify dimensions of the concept under examination, which gives basis to establish conceptualization of the concept under investigation by interacting with the beliefs, views, and assumptions concerning language teaching. In this study, CLT principles proposed in ESL literature (Canale \& Swain, 1980; Canale, 1983; Hyme, 1972; Savignon, 1983, 1997, 2000) formed the basis of Bhutanese ESL teachers' CLT conceptualization.

Communicative Language Teaching approach has come in vogue as many ESL and EFL contexts adopted it as potential approach in augmenting students' communicative competence. However, in many context, implementing the approach has been found challenging. One of the encumbrances in adopting CLT studies revealed was that teachers face difficulties in both understanding and adopting CLT, and implying a mismatch between the theory and teachers' understanding (Chang, 2011; Mangubhai et al., 2004, 2005; Thompson, 1996; $\mathrm{Wu}, 2008$ ). Personal beliefs, experiences, and cultural differences in perceiving the concept of communicative competence were seen to influence the teachers' conceptualization of CLT.

Teachers' lack of knowledge about tested communicative competence components such as linguistic, sociolinguistic, pragmatic, and discourse (Canale $\mathbb{E}$ Swain, 1980, Canale, 1983) are reflected in studies. For example, Nazari (2007) studied Iranian EFL teachers' understanding of communicative competence. He made a distinction between a socio-cultural tenet and linguistic competence, the broader and narrow view respectively of communicative competence. The findings indicated that the teachers remain unaware of the distinction. They had a narrower view both in defining the notion of communicative competence and organizing classroom activities which focuses more on linguistic competence. The researcher suggests that the teachers' lack of awareness about this distinction, for instance, is the cause for teachers' inclination towards linguistic competence, thus adhering to traditional method like grammar translation approach. This finding seems to reflect the case of Bhutan as well. LA Prairie (2013) interviewed policy makers, teachers, and students and observed the classroom teaching of Bhutanese ESL teachers to examine how facilitative is English language teaching in developing communicative competence of the Bhutanese students. He found that the classroom teaching was mostly focused on teaching grammar explicitly, and dominantly teacher-centered, where teachers give lecture and students listen passively. He concluded that Bhutanese teachers have lack knowledge of theoretical framework that supports language enrichment. However, the study does not account to how teachers conceptualize any particular language enriching theoretical framework like communicative competence (Hyme, 1972; Canale \& Swain, 1980).

Likewise, Sato and Kleinsasser (1999) examined the problems of Australian teachers who taught Japanese as a foreign language in using CLT. They found inconsistency between teachers' perceptions of CLT and classroom practices. The study suggested that the teachers' understanding about CLT was mostly influenced by their experience and teaching context. Concurrently, Mangubhai et al. (2005) investigated CLT practices by six Language Other Than English (LOTE) teachers in Japan and observed that the teachers basically developed conceptualization of CLT in two ways: from their work experience and the existing CLT theories. From what LA Prairie (2013) has claimed about Bhutanese teachers' lack of knowledge on language teaching theoretical framework, the findings reflected by Sato and Kleinsasser, and Mangubhai et al. might also depict the state of Bhutanese ESL teachers' situation.

On the other hand, studies have also empirically recorded the misconception that the teachers have about CLT. These misconceptions are often attributed to ESL and EFL teachers' digression from CLT practice and adherence to traditional language teaching approaches. Thompson 
(1996) and Wu (2008) reviewed papers exploring the misconception about CLT held by the foreign language and second language teachers. They observed that teachers believed that CLT means not teaching grammar, not developing skills other than speaking, mainly use of pair-work and role play, increase in teachers' workload, not providing timely corrective feedback on learners' errors, and avoidance of L1 use in the classroom. They maintained that these mis-conceptualizations have potentially effected CLT implementation in many contexts.

The empirical studies reviewed above suggest that teachers' beliefs, views and assumptions about CLT are among the factors preventing effective CLT implementation. In Bhutan, there is no record of studies except the one reviewed above, LA Prairie's (2013) study which explored the ESL teachers' awareness about the language teaching theoretical framework such as CLT. However, LA Prairie does not account to CTL

framework, which this study intent to explore specifically. Thus, this study explored the conceptualization of CLT by the Bhutanese ESL teachers. The research question "What are the conceptualizations of CLT by the Bhutanese ESL teachers?" guided this study.

\section{METHOD}

To understand the CLT conceptualization of Bhutanese ESL teachers, a mixed method study was conducted. However, only the qualitative data obtained from semi-structured interviews and class room observations are reported in this paper. In this study, the researcher conducted semi-structured interview to elicit participants' beliefs, views, and assumptions about language teaching and CLT practice. Burns (2000) stated that a semi-structured interview is one that, "rather than having a specific interview schedule or none all, an interview guide may be developed..." (p. 424). The researcher used this technique because it had potential to provide a direction without fixed wording or ordering. This permitted flexibility for the researcher to provoke responses for clarity and elaboration when necessary (Burns, 2000). It provided more information and insight on participants' understanding about CLT and their classroom practice.

In order to gain the primary data about the instructional practice of ESL teachers, the researcher observed classroom teaching. This enabled the researcher to obtain a clear picture about the English language class, and an insight into the association between teachers' conceptualization of CLT and their classroom practice. Kane, Sandretto and Heath (2002) contended that in studying teachers' beliefs and practice in teaching, a study that depends only on what teachers say about their classroom practice obtains incomplete story. So, they recommended direct observation as affective method to apprehend the teachers' classroom practice. Thus, it is employed in this study.

The study was conducted in Chukha district. Of 519 government schools in Bhutan, 41 were in Chukha (MoE, 2014). The participants for the semi-structured interviews were four ESL teachers. They were selected by following purposive sampling technique which allows the researcher to recruit potential participants based on their time limitation, logistic convenience, and subject relevance. In selecting interview informants, the researcher followed Patton's "maximum variation sampling" (in Li, 1999, p. 684) that allowed for maximum variation in participants' sex, school level, qualification, teaching experience, and teaching setting (see Table 1). However, for classroom observation, only two participants consented the researcher to observe their classes.

Table 1. Demographic information of the interviewees

\begin{tabular}{llllcl}
\hline Participants & \multicolumn{1}{c}{ Sex } & $\begin{array}{c}\text { School } \\
\text { level }\end{array}$ & $\begin{array}{c}\text { Education } \\
\text { Qualification }\end{array}$ & $\begin{array}{c}\text { Work } \\
\text { Experience }\end{array}$ & Teaching Setting \\
\hline Respondent1 & Female & Middle & M.A in Literature & 11 years & Urban \\
Respondent2 & Male & Primary & PTC & 13 years & Rural \\
Respondent3 & Male & Higher & M.A in Literature & 9 years & Semi-urban \\
Respondent4 & Female & Lower & B. Ed & 6 years & Urban \\
\hline
\end{tabular}


Regarding the interview questions, a set of 15 predetermined open-ended questions were asked. The questions were determined to expand and delve deeper understanding on participants' conceptualization of CLT in Bhutan. Whenever necessary, additional questions were asked to get deeper and elaborated response. The content validity of an interview questions was ensured by consulting three experts and computing Item Object Congruence (IOC) in accordance with Lynn's (1986) item acceptability criteria. Foreign Language Classroom Observation Protocol (FLCOP) developed by Hongboontri (2008) was adapted for observing the classroom teaching.

Before collecting the data, the researcher sought a formal permission from the Ministry of Education (MoE), District Education Office, Chukha, and the concerned principals of the participating schools. After permission was granted, the teachers were invited to take part in the study. The interviews were conducted during the free time with participants' consent. Classes were observed with consent from the participants. Each participant's lesson was observed at least thrice each.

The data collected from semistructured interviews and classroom observation was analyzed employing the concept of content analysis. The data were analyzed within the theoretical notion of CLT proposed by language scholars (Canale $\&$ Swain, 1980; Hyme, 1972; Lasser-Freeman 2000; Savignon, 1983, 1997, 2002). According to Fraenkel, Wallen and Hyun (2012), content analysis is a technique by which peoples' behavior can be studied by analyzing their communication.

\section{RESULTS AND DISCUSSION}

This section reports the results from the semi-structured interviews and classroom observation to answer the research question about what the conceptualizations of CLT by the Bhutanese ESL teachers are and what are the relation between the teachers' conceptualization and their classroom practices.
Conceptualization Complying CLT Principle

The results are presented under three categories; (i) Conceptualization complying with CLT principles, (ii) Conceptualization deviating CLT notion, and (iii) Conceptualization depicting limited knowledge of CLT.

The findings from this study revealed wide range of beliefs, views, and assumptions the respondents held about language teaching, matching the notion of CLT advocated in the literature. Four specific conceptualizations of CLT stated by respondents that comply with CLT notions were: 1) focus on developing communicative competence, (2) learning to use language for real life, (3) child-centered classroom, and (4) teaching of culture in language class.

\section{Focusing on Developing Communicative Competence}

All the respondents believed that the goal of language teaching should be in developing learners' communicative competence in English. Respondent\#3, remarked, "The approach focuses on developing learners' communicative competence." The respondent added that communicative classroom in Bhutan must enable the students to communicate in English without any challenge. Supporting this view, Respondent\# 1 maintained that the main focus of teaching English was to make the students competent in both speaking and writing. The respondent remarked:

The goal of my language teaching is to make my learners competent in using English. I encourage them to speak in the class. I do it by engaging them in various activities. I believe, with the interaction they make in the class they become more comfortable speaking in English, eventually making good in English.

Similarly, Respondent\#4, also shared that the main goal of language teaching was to develop learners' communicative competence. However, unlike others, it was observed during the classroom observation that the respondent used reading, which was explained that it was done as means to develop learners' communicative competence believing that reading makes learners more 
confident not only with the language but with ideas and knowledge.

From the analysis, it can be ascertained that the respondents hold a belief that CLT is a language teaching approach that focuses on developing learners' communicative competence. This belief upholds the principle of communicative language teaching, which depicts the respondents having right view about CLT.

\section{Learning to Use Language in Every-day life}

Learning to use language in real-life was one of the conceptions that the respondents had of CLT. Three respondents (Respondent\#1, 3 and 4) maintained that the main function of language is to communicate in real-life, and English language teaching in Bhutan should prepare students to use English in their daily life. In this regard, Respondent\#4 noted, "I think, if students cannot use English in day-to-day life, I don't see any reason why they have to learn it. CLT certainly helps students to communicate better." Similarly, Respondent\#3 described how the students, despite knowing the rules of language, fail to communicate well in English:

Even when the students know the rule of grammar, they still fail to speak. It is due to the lack of practice. It is same with writing; they cannot write what they know. To make them used to use English, I make my class interactive. It is done to make them comfortable in using English outside the classroom.

In this light, Respondent\#4 described how he makes classroom communicative to make students enhance authentic communication skills in English:

Most of the time I make my classroom communicative. I use many activities that gives opportunities for the students to interact. Some of the activities I use often are role plays, group discussions, pair work, and of course, even whole class discussion. I also use presentation and question-answer techniques.

However, during the classroom observation, it was observed that respondents mostly explained the text strictly, and rarely engaged children in interaction. It was seen that classroom interaction was mostly stuck to teacher asking questions which demand yes/no answer, and student responding yes or no in chorus. This was common across all lessons observed with both teachers.

Thus, from the above responses it can be construed that the respondents viewed CLT as a language teaching approach that develops language learners' ability to use English in real life. However, in real teaching time, they tend to digress from their beliefs, depriving students from having authentic conversation in the classroom. This shows though they have rightly view on CLT as emphasizing use of authentic language, they provide inadequate time to the students to practice language.

\section{Student-centered teaching approach}

Respondents unanimously believed that CLT is a student-centered language teaching approach. The respondents contended that building communicative competence needs adopting interactive and activity-based teaching techniques to provide students with opportunities for active involvement in learning. This is well asserted in Respondent\# 1's statement:

If a teacher does all the talks and not let the students practice, there is hardly any chances of teaching the students how to use language. I think, classroom is a place where they practice by doing, not just listen to their teacher passively. We cannot expect the students learn just from listening to teachers and understanding the text used in the classroom. Involving the students in classroom activities not only makes them learn English in context, but also build confidence to use it in their daily life. Communicative class, in my view, should make the students use English most of the time.

The respondents portrayed awareness of various communicative activities that make their language classes student-centered and activity-based. For instance, Respondent\#3 illustrated how English class is made student-centered as below:

I conduct various activities to make my classroom student-centered. Usually, I provide them with some information on the lesson topic and then engage them in the activities. I feel like trying different activities based on the nature of topic I am teaching. For example, in my last class, I made my students design 
'comic stripes' in groups. Students developed comic from a story of their choice. Other than that, I also make students do presentation, group works, and pair works too.

The respondents' description of their practices indicates their beliefs on teaching of English concurs CLT principles. However, as mentioned in earlier result, from the classroom observation, it was viewed that their classroom practices least represented their beliefs. The result shows despite the teachers' intention to make child-centered classroom; the classroom teaching remain largely teacher dominated.

\section{Teaching culture in language class}

From the sociolinguist's perspective, teaching culture in language class enhances students' knowledge on using the language appropriate to context and situation (Hyme, 1972; Savignon, 1983, 1997, 2000). Affirmatively, all respondents stated that Bhutanese children need to be introduced to foreign cultures in order to develop appropriate communicative behavior. Compounding rest of the respondents' view, Respondent\#2 stated that "language comes with culture, so we must understand the culture of native speakers. Otherwise, what we think is right here would not be right there." This was best illustrated by Respondent\#3:

We need to teach the differences in expressing ourselves. Here we consider polite when somebody puts his/her eyes down and speak in lower voice when talking to someone elder or higher rank. But that would be a sign of low confidence in English culture. In their culture, looking straight and speaking loud and clear is right behavior; this might be considered disrespectful here.

On the other hand, Respondent\#3 showed hesitation in teaching second language culture in Bhutan. Teaching foreign culture was viewed to be demeaning the local culture.

Language comes with culture and if we are not careful about teaching language culture, which means introducing foreign culture, it could undermine our own culture. Though, I agree it needs to be taught up to some extent, I would not like to make it dominant culture just to develop English language education in Bhutan.
Overall, the respondents hold beliefs that comply with CLT principles in four areas. They believed that the main goal of CLT as to teach communication skills, CLT as teaching language for real life use, children-centered teaching methods, and teaching of culture in the classroom. However, their classroom teaching deviate to their beliefs. This also show that although the teachers have certain right conceptualization about CLT, their practice still adhere to traditional teaching method.

\section{Conceptualization deviating from CLT notion}

The interviews revealed two beliefs, views, and assumptions that the respondents held about CLT, those are disparate to CLT principles professed in the CLT literatures (Canale \& Swain, 1980; Hyme, 1972; Savignon, 1983, 1997). They were: (1) zero use of mother tongue, and (2) teaching only listening and speaking.

\section{Not Using Mother tongue}

All respondents responded that CLT means not using mother tongue in English language class. The techniques like code switching and code mixing are viewed as impediment in language learning process. This is described by Respondent\#2: "Using mother tongue in classroom only encourages students to communicate in their local language." Respondent\#4 reiterated a similar view:

Since my students are poor in English, they feel more comfortable using their mother tongue. So, if they are allowed to use mother tongue in the class, they will not bother to use English. Likewise, if the teacher uses mother tongue students imitate the teacher. Even with senior students, given a chance, they would not use English. So, I feel that teacher and students should refrain from using mother tongue in English classroom.

Although the respondents said that they use mother tongue to overcome challenges to convince the learners with some abstract concepts, they maintained that as far as possible they try not to use the mother tongue. The respondents' conviction was that by abstaining mother tongue in classroom language, they could influence 
students develop habit of using English.

Respondent\# 1's statement bears the view:

The English teachers should not use the students' mother tongue in the classroom.

Since teachers are the model of language user in the class, if the teachers use the first language so often, the students will be rather confused and pick up the habit of using their mother tongue hand in hand with English, which I think is not good.

Correspondingly, the teacher was observed not using any of the local languages at all in the classroom.

\section{Teaching only Listening and Speaking}

The results indicated that respondents viewed CLT as focusing mostly on listening and speaking skills, while neglecting reading and writing. Though the respondents maintained that their main focus of teaching English is to develop students' communicative competence, their conceptions of communicative competence were bound to language accuracy and fluency. When asked to define communicative competence, three respondents (Respondent\#2, 3 and 4) defined it as the ability to speak fluently and accurately. Respondent\#2 stated, "My focus in teaching English is to develop students' ability to speak fluently with correct grammar and pronunciation."

Generally, the participants held two conceptions that deviate from CLT principles. They believed CLT means not using mother tongue and it means teaching only listening and speaking.

\section{Lack of Awareness about CLT}

Results revealed that participants lacked awareness about CLT. Three respondents (Respondent\#1, 2, and 3) admitted that they never heard of CLT. Nevertheless, Respondent\# 1 acknowledged that the respondent has heard about it, but has little knowledge about it. Respondent conceded, "I came across this word (CLT) somewhere, but I did not take the trouble of going through it in detail." Further, when asked to define CLT, it was defined with hesitation: "Maybe an approach to enhance communicative language; the ability to speak fluently, correctly, and write well."

Other respondents defined CLT based on the term and their understandings. Respondent\#3 defined it: "It must be about how to communicate effectively, how to understand others, how to make others understand what you are saying, so it must be something like that".

Similarly, respondent\#2 described:

I am not sure; I am hearing the term for the first time. But I think, as language teachers, we have been teaching our students to communicate in English. Maybe I was partially fulfilling the aspects of communicative language teaching though I didn't hear the term CLT before. Because communication skills by any means come in the central of teaching English language. So, I think, it is an approach to teach how to communicate fluently and correctly.

Overall, the results of this study revealed that CLT conceptualization held by Bhutanese ESL teachers largely complied with the notion of CLT proposed by the scholars. They were CLT as a language teaching approach that focuses on developing communicative competence, teaching language for real life, child-centered teaching, and teaching culture in the second language classroom. However, two notions deviating from CLT concepts were found: CLT as not using mother tongue in teaching English, and teaching only listening and speaking skills. Finally, the study also uncovered the fact that the ESL teachers are not aware of CLT approach.

The results found that the respondents believed CLT as teaching for developing communicative competence which was in consistent to the goal of CLT posited by Larser-Freeman (2000). Respondent pointed out that everything done in CLT classroom is driven by a communicative intention. Similarly, CLT emphasizes on preparing the students for communication beyond the classroom (Savignon, 1983, 1997). This study found that the respondents focused on enabling the learners to communicate in real life situation as well. CLT treats teaching of culture essential for developing communicative skill (Guilherme, 2000). This notion has engendered the idea of 
intercultural communicative competence, the knowledge, motivation and skills to interact effectively and appropriately with members of different cultures (Wiseman, 2002).

Corresponding to this notion, the respondents viewed teaching culture in the classroom as essential to develop intercultural sensitivity. Furthermore, the results revealed that the respondents viewed CLT as student-centered teaching in compliance with Richardson's (2006) definition of CLT as child-friendly and interactive approach.

On the other hand, the results also revealed respondents' view of CLT as not using mother tongue in teaching English. Wu (2008) and Thomson (1996) reported these notions as common misconceptions the teachers held about CLT in China and other contexts. Wu maintained that the notion of zero-mother-tongue emerged from traditional method such as audio-visual and direct methods. In task-based learning (one form of CLT), mother tongue can be used to suit the situations, such as explaining complex ideas or concepts (Turnbull 2001 as cited in $\mathrm{Wu}, 2008)$. However, the issue of overusing mother tongue merits discussion in Bhutanese context where children have a common first language (Dzongkha). This was found as an issue in monolingual country like Thailand, China, and Taiwan (Wanchai, 2011, Chang, 2011; Nazary, 2008). Wanchai found that Thai ESL teachers used L1 exceedingly in the classroom which limited opportunity for the students to practice target language in the class. Therefore, $\mathrm{Wu}$ warned the language teachers that "A teachers' goal needs to be to find the right balance between the use of L1 and L2, which makes sure students understand and that the same time maximizes the use of the target language" ( $p$. $52)$.

Thomson (1996) and $\mathrm{Wu}(2008)$ also pointed that another common misconceptualization the teachers have about CLT is, teachers think CLT focuses only on listening and speaking, and ignores the need of developing writing and reading skills. Unfortunately, the respondents in this study held identical views too. Though CLT proposes oral instructions as effective means to teach language, Savignon (1983, 1991, 1997) and Lasser-Freeman (2000) reaffirmed that CLT balances its emphasis on all traditional language skills.

Finally, the study found that ESL teachers were either unaware of existence of CLT approach or had limited knowledge about the approach. Three respondents admitted that they never heard about CLT, and one conceded of knowing little about it. Furthermore, the concept of communicative competence as conceived by the four respondents was strictly bound to fluency and accuracy, not accounting to sociolinguistic, discourse and pragmatic dimensions of competence. The findings, therefore, endorses LA Prairie's (2013) study which concluded that Bhutanese ESL teachers have lack awareness about theoretical framework of language sensitive teaching approaches. Inadequacy in grasping the concepts of communicative competence could be, therefore, one of the reasons for teachers' inhibition in practicing communicative approach. Mangubhai et al. (2007) offered a clear explanation to the phenomenon observed in this study. They suggested that teacher might have two conceptualizations: a theoretical one based on study, and a practical one based on classroom experiences.

\section{CONCLUSION}

From the findings of this study, it can be concluded that the CLT conceptualization that Bhutanese ESL teachers hold are constructed based on their teaching experiences rather than from theoretical knowledge. The study suggests that the inadequacy of theoretical knowledge of Bhutanese ESL teachers about CLT may be affecting in translating the emphasis on incorporating communicative dimensions the national curriculum makes. However, as Anderson (1993) noted that the CLT approach found based on western context may not be directly applicable in ESL and EFL contexts. To enhance their practical knowledge, thus, input on theories of communication competence and communicative teaching frameworks would offer clear information regarding the process in localizing the concept and developing 
Jigme Dorji

Communicative Language Teaching as Conceptualized by Bhutanese English as Second Language Teachers

effective methods and techniques in teaching communication skills.

\section{REFERENCE}

Asassfeh, S. M. Khwaileh, Al-Shaboul \& Alshaboual. (2012). Communicative language teaching in an EFL context: Leaners' attitude and perceived implementation. Journal of Language Teaching and Research, 3(3), 525-535.

Anderson, J. (1993). Is the communicative approach practical for teaching English in China? Pros and cons. System, 21, 417-480.

Burns, R. (2000). Introduction to research methods. French's Forest NSW: Australia Longman.

Canale, M., \& Swain, M. (1980). Theoretical bases of communicative approaches to second language teaching and testing. Applied linguistics, 1(1), pp. 1-38.

Chang, M. (2011). Factors affecting the implementation of communicative language teaching in Taiwanese college English classes. ELT, 4(2), 312.

Curriculum and Professional Support Division. (2006). English curriculum guide for teachers. Thimphu: Ministry of Education.

Dorji, J. (2005). Quality of education in Bhutan: The story of growth and change in the Bhutanese education system. Phuntsholing: KMT.

Hongboontri, C. (2008). Workplace organization factors and professional development of university English as a foreign language (EFL) teachers: Lesson from Thailand. Malaysia: Sasbadi Sdn, Bhd.

Kane, R., Sandretto, S., \& Heath, C. (2002). Telling half the story: A critical review of research on the teaching beliefs and practices of university academics. Review of Educational Research, 72(2), 177-228.

Kirkpatrick, R., \& Gyem, K. (2012). Washback effects of the new English assessment system on secondary schools in Bhutan. Language Testing in Asia, 2(4), 5-32.

Larser-Freeman, D. (2000). Techniques and principles in language teaching. Oxford: Oxford University Press.

Lynn, M. R. (1986). Determination and quantification of content validity. Nursing Research, 35, 382-385.

Mangubhai, F., Marland, P., Dashwood, A., \& Son, J. B. (2005). Similarities and differences in teachers' and researchers' conceptions of communicative language teaching: Does the use of an educational model cast a better light? Language teaching research, 9(1), 31-66.

Ministry of Education. (2014). Annual education statistics. Policy and Planning Division, Ministry of Education: Royal government of Bhutan.

Nazari, A. (2007) EFL teachers' perception of the concept of communicative competence. ELT Journal, 61(3), 202-210.

Nazary, M. (2008). The role of L1 in L2 acquisition: Attitudes of Iranian university students. Novitas-Royal, 2(2), 138-153.
Richard, J. C. (2006). Communicative language teaching today. Cambridge: Cambridge University Press.

Richard, J., \& Rodgers, T. (1986). Approaches and methods in language teaching. Cambridge: Cambridge University Press.

Royal Education Council. (2012). The national education framework: Shaping Bhutan's future. Thimphu: Royal Education Council.

Sato \& Kleinssaser (1999). Communicative language teaching (CLT): Practical understanding. The Modern language journal, 8(3), 494-517.

Savignon, J. S. (1983). Communicative competence: Theory and classroom practice. Reading, MA: Addison-Wesley.

(1997). Communicative competence: Theory and classroom practice. Reading, MA: AddisonWesley.

(1991). Communicative language teaching: State of the art. TESOL Quarterly, 25(2), 261-277. (2006). Beyond communicative language teaching: What's ahead? Journal of Pragmatics, 39, 207-220.

Swain, M. (1980). A critical look at the communicative approach. ELT Journal, 39(1), 2-12.

Thomson, G. (1996). Some misunderstanding about communicative language teaching. ELT Journal, 50(1), 9-15.

Wanchai, P. (2011). Teachers' conceptualizations of CLT approaches and their practice: A closer look into Thai EFL classrooms. Unpublished Thesis, Master Degree, Faculty of Liberal Arts, Mahidol University.

Wu, W. (2008). Misunderstandings of communicative language teaching. English Language Teaching, $1(1), 50-53$ 